\title{
Reality monitoring judgments of other people's memories
}

\author{
MARCIA K. JOHNSON \\ Princeton University, Princeton, New Jersey \\ and \\ AURORA G. SUENGAS \\ Universidad Complutense, Madrid, Spain
}

\begin{abstract}
The characteristics of witnesses' descriptions of events were varied by manipulating the type of covert rehearsal in which witnesses engaged before they described the events. Descriptions were more likely to be attributed by judges to perception than to imagination if witnesses had thought about perceptual aspects of events (e.g., colors and sounds) than if they had thought about apperceptive aspects (thoughts and feelings) before giving their descriptions. Thus, how people think about events may affect how they describe them, and people use some of the same cues to judge the source of other people's memories as they use in making attributions about the source of their own memories (Johnson \& Raye, 1981).
\end{abstract}

Memories for perceived and imagined complex events differ in various characteristics, and people use such differences to discriminate between autobiographical memories of perceived and imagined events (Johnson, Foley, Suengas, \& Raye, 1988; Suengas \& Johnson, 1988; also see Johnson, 1985, 1988; Johnson \& Raye, 1981). It follows that people would use these same differences in trying to ascertain the origin of other people's memories (e.g., Schooler, Gerhard, \& Loftus, 1986). Descriptions of events may reflect not only characteristics of initial memories for the events, but also the memorial effects of subsequently thinking and/or talking about the events (Johnson et al., 1988; Suengas \& Johnson, 1988). In the present study, we were interested in (1) the effects of rehearsal on witnesses' descriptions of events and (2) the effect of witnesses' rehearsal on judges' attributions about the origin of witnesses' memories. To manipulate the type of rehearsal in which witnesses engaged, we had them think about either perceptual (e.g., colors) or apperceptive (e.g., feelings) aspects of perceived and imagined events before they described them.

\section{PHASE 1: COLLECTION OF THE DESCRIPTIONS}

\section{Method}

A total of 36 students from the State University of New York at Stony Brook received either course credit or payment for their participation on 2 consecutive days.

Day 1: Acquisition and rehearsal. Subjects participated in groups of 4. Each subject perceived six situations and imagined six situations

Preparation of this paper was supported by National Science Foundation Grant BNS-8510633. Correspondence regarding this article should be sent to Marcia K. Johnson, Department of Psychology, Princeton University, Princeton, NJ 08544-1010. (e.g., wrapping a parcel, having coffee and cookies). On perception trials, the subjects actually engaged in the situations (e.g., they were given a box, a piece of paper, and some tape in order to wrap a parcel). On imagination trials, the subjects heard a script describing the situation and were given time between sentences to imagine the event. Situations were counterbalanced across subjects so that any given situation was perceived and imagined by an equal number of subjects.

The subjects then were randomly assigned to one of three rehearsal conditions. The subjects in the control group were discharged until the next day. The subjects in the other two groups were instructed to think about either perceptual or apperceptive aspects of six of the situations (three perceived and three imagined), six times each, in random order. On each rehearsal trial, the subjects were cued with an event label and a particular aspect of the event to rehearse, for example, "think about the colors of the parcel" (perceptual condition), or "think about any positive feelings that you had while having the coffee and cookies" (apperceptive condition). Particular events were assigned equally often across subjects to each condition.

Day 2: Rehearsal and collection of descriptions. The subjects in the perceptual and apperceptive rehearsal groups were again instructed to think about the events according to the same procedure used on Day 1. At the end of the second session, these subjects had not rehearsed six of the situations, and had rehearsed the six other situations 12 times each. (For more detail on situations and rehearsal instructions, see Suengas \& Johnson, 1988, Experiment 1.) The subjects in the perceptual and apperceptive groups then were instructed to describe the six rehearsed events. Control subjects also described six of the events. Subjects participating in Phase 1 were witnesses, and subjects in Phase 2 were judges.

\section{Results and Discussion}

The 216 descriptions ( 36 subjects $\times 6$ descriptions each) were taped and transcribed. Two transcripts were dropped (one subject from each of the control and apperceptive groups could not describe one imagined event), and 17 transcripts from imagined events ( 4 from the control, 12 from the apperceptive, and 1 from the perceptual group) were edited to omit phrases (e.g., "I imagined ...") that made it too obvious that the events had been imagined. No changes were made in any other transcripts. 
Table 1

Phase 1: Mean Values of Categories Scored from Witnesses' Transcripts

\begin{tabular}{|c|c|c|c|c|c|c|c|c|}
\hline & \multicolumn{8}{|c|}{ Rehearsal Condition } \\
\hline & \multicolumn{2}{|c|}{ Control } & & \multicolumn{2}{|c|}{ Perceptual } & & \multicolumn{2}{|c|}{ Apperceptiv } \\
\hline & $\mathbf{P}$ & I & & $\mathbf{P}$ & $\mathrm{I}$ & & $\mathbf{P}$ & I \\
\hline No. Words & 119 & 101 & $=$ & 83 & 98 & $=$ & 85 & 91 \\
\hline Colors & 2.4 & 1.7 & $<$ & 4.5 & 3.7 & $>$ & 0.4 & 1.4 \\
\hline Numbers & 3.3 & 2.0 & $=$ & 2.5 & 2.3 & $>$ & 0.7 & 0.7 \\
\hline Feelings & 3.2 & 2.3 & $=$ & 1.9 & 2.7 & $=$ & 3.7 & 3.3 \\
\hline Thoughts & 3.7 & 3.2 & $>$ & 1.4 & 0.4 & $<$ & 3.0 & 2.2 \\
\hline Spatial & 2.7 & 1.7 & $=$ & 3.5 & 3.8 & $>$ & 0.6 & 0.9 \\
\hline People & 5.4 & 5.1 & $=$ & 5.5 & 2.3 & $=$ & 2.7 & 2.7 \\
\hline
\end{tabular}

Characteristics of the event descriptions. Two scorers evaluated the transcripts according to seven categories: number of words, and how often colors, numbers, feelings, thoughts or ideas, people, and spatial references (i.e., "right," "left," "on top," "above," "'below") were mentioned in each description. Both scorers agreed $100 \%$ in all measures except those related to feelings and thoughts, where agreement was $81 \%$. Initial disagreements were resolved by discussion. Mean values for each measure are shown in Table 1 . A $2 \times 3$ (origin $\times$ rehearsal condition) mixed analysis of variance was performed on each measure, with alpha level set at .05 .

Although perceived events received higher scores than imagined events in most of the comparisons, there were no main effects of origin of the event and no interactions of origin and type of rehearsal. Main effects for type of rehearsal were found in various measures [i.e., mention of colors, $F(2,33)=8.97, M S e=7.05$; numbers, $F(2,33)$ $=5.21, M S e=5.23$; thoughts, $F(2,33)=6.42, M S e$ $=12.48$; and spatial references, $F(2,33)=6.42, M S e$ $=7.95$ ]. Subsequent planned analyses (summarized in Table 1) indicated that descriptions made by witnesses who thought about the perceptual aspects of the events contained more references to colors than did descriptions made either by witnesses who thought about apperceptive aspects $[F(1,22)=5.17, M S e=9.68]$ or by control witnesses $[F(1,22)=28.03, M S e=4.41]$. Numbers and spatial positions were not mentioned as often in descriptions from apperceptive witnesses as in descriptions from control $[F(1,22)=19.18, M S e=2.40 ; F(1,22)=4.42$, $M S e=5.78]$ or perceptual $[F(1,22)=5.78, M S e=$ 6.06); $F(1,22)=13.62, M S e=7.49$ ] witnesses. Thoughts experienced at the time of the event were mentioned equally often by control and apperceptive witnesses. Witnesses who thought about perceptual aspects of the events did not mention their thoughts about the events as often as did witnesses from the other two groups [perceptual vs. control, $F(1,22)=4.75, M S e=17.54$; perceptual vs. apperceptive, $F(1,22)=12.05, M S e=$ 2.91]. There were no differences among the three groups in the number of words used to describe the events, mentions of feelings, and references to people.

The lack of significant differences between descriptions for perceived and imagined events was surprising, espe- cially given Schooler et al.'s (1986) results. Also, under similar circumstances, subjects generally rate memories for perceived events higher than memories for imagined events in, for instance, visual and contextual attributes (Johnson et al., 1988, Suengas \& Johnson, 1988). The results were, however, in the expected direction, especially in the control condition. Furthermore, in a subsequent study (Hashtroudi, Johnson, \& Chrosniak, 1989) in which recall protocols were scored as in the present study, perceived events were significantly higher than imagined events on a number of measures. One difference between the two studies is that Hashtroudi et al. used written recall, whereas we used oral recall in the present study. Perhaps people are naturally more expansive when talking, or maybe they use more exacting memory-editing criteria when putting things into writing. Also, oral recall might be more subject to social factors, such as wanting to produce an interesting or cohesive narrative. There were several other differences between studies, so no firm conclusions can be drawn, but an interesting possibility is that people embellish imagined events more than perceived events when recalling orally. If so, this would tend to make memories for perceived and imagined events appear more similar.

\section{PHASE 2: ORIGIN JUDGMENTS}

Although we found no differences between transcripts for perceived and imagined events, descriptions were clearly affected by rehearsal condition: descriptions from the perceptual group contained more references to colors, numbers, and spatial arrangements than did descriptions from the apperceptive group. Remembered perceptual and spatial details are generally taken by a rememberer as signs that an event was perceived (Johnson, 1985; Johnson et al., 1988, Study 2). Thus Phase 2 assessed whether rehearsal condition would affect new subjects' judgments about the origin of the events.

\section{Method}

A total of 102 undergraduate students from the State University of New York at Stony Brook, who had not participated in Phase 1 of the experiment, received course credit for their participation. The 214 tran- 
scripts collected in Phase 1 were used. The subjects, tested in groups of 6, were given booklets containing 12 transcripts, each one corresponding to one of the 12 situations used in Phase 1. Four descriptions (2 perceived and 2 imagined) came from control witnesses, 4 from witnesses in the perceptual group, and 4 from witnesses in the apperceptive group. The subjects were asked to judge the origin (perceived or imagined) of each transcript, and to give the reasons for their decisions.

\section{Results and Discussion}

Judgments. Table 2 shows the overall frequencies of subjects' responses. Consistent with our scoring from Phase 1 , the subjects could not reliably differentiate perceived from imagined transcripts (overall mean correct identification of origin $=52.33 \%$ ). Also consistent with our scoring from Phase 1 , the tendency to attribute descriptions to perception was more marked for descriptions made after rehearsal of perceptual aspects than for descriptions made after rehearsal of apperceptive aspects. This was true for descriptions of both perceived $\left(\chi^{2}=5.3\right)$ and imagined $\left(\chi^{2}=3.84\right)$ events. (Although these data do not meet the underlying assumption of independence of observations of the chi-square test, because the same subjects contributed ratings in all cells, another index of reliability is the fact that the comparison of judgments after perceptual and apperceptive rehearsal was similar for both perceived and imagined events.) Thus the overall results indicated that subjects' judgments were affected by the type of rehearsal in which witnesses had engaged.

Subjects' reasons. Subjects provided 1,958 reasons for deciding whether descriptions corresponded to perceived or imagined events, and these were classified according to 20 categories (e.g., the description was detailed, vague, too short, too long) by three independent judges. Whenever two or three judges agreed upon a category for a reason, the classification was accepted. Consensus by this criterion accounted for $94 \%$ of the classifications. Instances in which the three judges disagreed $(6 \%$ of the total) were included under the category of " other or no reason."

Subjects (whether they were right or wrong) reported that events had been perceived if the description seemed "real" (mentioned in $16.46 \%$ of the reasons; e.g., "It sounds like a good account of the situation"), if it con-

Table 2

Phase 2: Overall Frequency of Judges' Responses According to the Origin and Rehearsal Condition of the Descriptions

\begin{tabular}{clcc}
\hline \multirow{2}{*}{ Origin } & $\begin{array}{c}\text { Rehearsal Condition } \\
\text { (Witnesses) }\end{array}$ & \multicolumn{2}{c}{ Judges' Responses } \\
\cline { 3 - 4 } Perceived & Control & Perceived & Imagined \\
& Perceptual & 121 & 83 \\
& Apperceptive & 105 & 76 \\
Imagined & Control & 105 & 99 \\
& Perceptual & 121 & 89 \\
& Apperceptive & 99 & 105 \\
\multicolumn{2}{c}{ Total Frequency } & \multicolumn{2}{c}{1,224} \\
\hline
\end{tabular}

tained visual or other sensory information (15.24\%; e.g., "Describes the texture of the paper"), if it was "detailed" (13.83\%; e.g., "Describes everything clearly with details"), and if it was "simple"' (8.18\%; e.g., "Explains basics without getting off the subject"). Subjects also believed that events were perceived if the witness "sounded confident"' (5.2\%; e.g., "Knew what he wrote, no hesitations") and if they could relate to what the witness was describing $(4.52 \%$; e.g., " I know when I write on a slippery desk the paper goes all over the place"').

Subjects (again, right or wrong) reported that they believed that events had been imagined if the description seemed "unreal" or dreamlike or if it sounded like an intention (mentioned in $17.09 \%$ of the reasons; e.g., "Is dreaming, or under hypnosis"), if it "lacked content" (11.73\%; e.g., "Did not explain anything"), and if it was "vague"” $(4.36 \%$; e.g., "The way he describes the picture is dim and vague"). Wrong use of language $(8.49 \%$; e.g., "Babbling on like the person is trying to avoid explaining") and faulty logic (7.60\%; e.g., "Does not eat the food, so how would he know the taste") were also taken as evidence for imagination. If the witness sounded "unsure" (12.58\%; e.g., "Seems like a wimp and is indecisive") or was unable to remember certain aspects of the situation (4.13\%; e.g., "Only remembered the obvious"), subjects tended to believe that the events had been imagined rather than perceived.

In summary, judges thought that descriptions were perceived more often than imagined if they came from witnesses who had rehearsed perceptual aspects of events than if they came from witnesses who had rehearsed apperceptive aspects of events. The most straightforward interpretation is that perceptual witnesses mentioned colors, numbers, and spatial arrangement more often than witnesses who had rehearsed apperceptive aspects of the events. The relative cue value for reality monitoring of various types of perceptual and apperceptive information remains to be sorted out. For example, one could create experimenter-generated descriptions and manipulate references to, say, color independently of references to spatial location. The general importance, however, of perceptual and contextual details not only was reflected in the fact that judges' attributions were affected by witnesses' rehearsal condition, but also was reflected in the reasons given by subjects for their judgments. Furthermore, our subjects judged witnesses' credibility on the basis of reasons similar to those used in reality monitoring judgments about one's own memories (Johnson, 1985, 1988; Johnson et al., 1988, Study 2) and those used in actual courtrooms (Undeutsch, 1982, 1984). These results are consistent with results obtained by Schooler et al. (1986) using an eyewitness memory paradigm. The way people think about past events affects the way they are subsequently rated (Suengas \& Johnson, 1988) and described (Phase 1), as well as the likelihood that they will seem to others to reflect perceived events (Phase 2). 


\section{REFERENCES}

Hashtroudi, S., Johnson, M. K., \& Chrosniak, L. (1989). Aging and qualitative characteristics of memories for perceived and imagined complex events. Manuscript submitted for publication.

Johnson, M. K. (1985). The origin of memories. In P. C. Kendall (Ed.), Advances in cognitive-behavioral research and therapy (Vol. 4, pp. 127). New York: Academic Press.

Johnson, M. K. (1988). Discriminating the origin of information. In T. F. Oltmans \& B. A. Maher (Eds.), Delusional beliefs: Theoretical and empirical perspectives (pp. 34-65). New York: Wiley.

Johnson, M. K., Foley, M. A., Suengas, A. G., \& Raye, C. L. (1988). Phenomenal characteristics of memories for perceived and imagined autobiographical events. Journal of Experimental Psychology: General, 117, 371-376.
Johnson, M. K., \& Raye, C. L. (1981). Reality monitoring. Psychological Review, 88, 67-85.

SchoOler, J. W., Gerhard, D., \& LofTus, E. F. (1986). Qualities of the unreal. Journal of Experimental Psychology: Learning, Memory, \& Cognition, 12, 171-181.

Suengas, A. G., \&ohnson, M. K. (1988). Qualitative effects of rehearsal on memories for perceived and imagined complex events. Journal of Experimental Psychology: General, 117, 377-389.

UNDEUTSCH, U. (1982). Statement reality analysis. In A. Trankell (Ed.), Reconstructing the past: The role of psychologists in criminal trials. Deventer, The Netherlands: Kluwer.

UNDEUTSCH, U. (1984). Courtroom evaluation of eyewitness testimony International Review of Applied Psychology, 33, 51-67.

(Manuscript received August 11, 1988.)

\title{
Announcement
}

\author{
Second International Facet Theory Conference \\ University of Surrey, Guildford, England \\ July 4-6, 1989
}

CALL FOR PAPERS

Papers on any application or aspect of facet theory are welcome. While the diverse application of facet theory will be reflected in the content of the conference, it is expected that the major substantive focus of the conference will reflect the principal areas of activity in the social sciences. In addition, there will be sessions exploring methodological and statistical developments related to facet theory.

At present, provisional sessions have been proposed in the areas of organizational psychology, environmental psychology, sociology, developments in research methodology, clinical psychology, social psychology, and statistics. It is likely that further sessions will be added.

Facilities will be available for the demonstration of developments in computer applications and analysis in facet theory.

Selected papers will be published following the conference.

Submission of papers: An abstract and summary (the summary to be a maximum of 4 pages) should be submitted, by mail, fax, or electronic mail via JANET (which links to EARN and BITNET) to David Canter or Ian Donald, at the addresses given below, by March 31, 1989.

Further information, including details about accommodation and cost, may be obtained from Ian Donald.

Mail address: Department of Psychology, University of Surrey, Guildford, Surrey GU2 5XH, U.K. Electronic Mail: National address-PSY160.@SURREY.SYSH; International addressPSY160.@UK.AC.SURREY.SYSH. Fax (0483) 300803. Telephone (0483) 571281, Ext. 2900. 